\title{
Antifungal activities of essential oils of Syzygium aromaticum, Piper betle, and Ocimum sanctum against clinical isolates of canine dermatophytes
}

\author{
Jareerat Aiemsaard, Korawuth Punareewattana* \\ Department of Pharmacology and Toxicology, Faculty of Veterinary Medicine, Khon Kaen University,
} Khon Kaen 40002 Thailand

*Corresponding author, e-mail: korawut@kku.ac.th

Received 21 Dec 2016

Accepted 12 Jul 2017

\begin{abstract}
Current antifungal drugs for canine dermatophytosis are effective but may cause adverse effects or drug resistance. In this study, three essential oils from Syzygium aromaticum (L.) Merr. \& Perry, Piper betle, and Ocimum sanctum were investigated for their antifungal activities. Fungal organisms were standard strains and clinical isolates of Trichophyton mentagrophytes, Microsporum canis, and Microsporum gypseum. Minimum inhibition concentration (MIC) and minimum fungicidal concentration (MFC) were evaluated. The composition of the essential oils was determined by GC/MS analysis. MIC and MFC tests indicated that the antifungal activities of these three essential oils were high (MIC range $0.2-1.6 \mu \mathrm{l} / \mathrm{ml}$ ) and fungal samples from both sources had similar sensitivity to antifungal drug and essential oils. The results of essential oil analysis revealed that eugenol and its derivatives were the major components possessing antifungal activity. In conclusion, this study demonstrated the potential of all three essential oils as highly effective antifungal agents against canine dermatophytes.
\end{abstract}

KEYWORDS: antidermatophytic activity, volatile oil, dermatophytosis, antifungal agent

\section{INTRODUCTION}

Dermatophytosis is a common skin disease in both human and animals worldwide. The major pathogens are in the genera of Epidermophyton, Trichophyton, and Microsporum. The common dermatophytes in dogs are Trichophyton mentagrophytes, Microsporum canis, and Microsporum gypseum $^{1}$. The clinical symptoms are generally mild, but the significance of the disease is its zoonotic ability and costly and time-consuming therapy. As most families nowadays have pets in their houses and pethuman interaction is increasing, dermatophytosis transmitted via direct contact with dogs or cats is a common scenario. This zoonotic infection poses a greater risk for immunocompromised people ${ }^{2}$.

Antidermatophytic drugs include several chemical groups, and the important drugs are griseofulvin, terbinafine, and azole drugs such as ketoconazole and itraconazole ${ }^{3}$. Even though they are effective, their adverse effects such as toxicities and drug resistance are of great concern. As dermatophytosis needs long-term therapy, the toxicities of antifungal drugs may be unavoidable. For example, ketocona- zole can inhibit adrenal steroid synthesis, and griseofulvin can cause gastrointestinal irritation and hepatotoxicity ${ }^{4}$. Chronic infection and re-occurrence are also a common nature of dermatophytosis, and a consequence is repetitive treatment which can cause the development of drug resistance. In addition, antifungal activities of azole agents, griseofulvin, and terbinafine are fungistatic which could contribute to the emergence of drug resistance ${ }^{5}$. These adverse effects are solid reasons for discovery and development of novel antifungal agents.

Essential oils are complex mixtures from plant origins which have been used for many purposes including use as pharmaceuticals. The constituents of essential oils differ based on their origins. Various biological activities have been reported including antimicrobial, anti-inflammatory, antimutagenic, antidiabetic and anticancer activities ${ }^{6}$. Recent studies have demonstrated the antidermatophytic activities of essential oils of several plant species, for example, Artemisia spp. ${ }^{7}$, Cinnamomum spp. ${ }^{8}$, Allium spp. ${ }^{9}$, Nigella spp. ${ }^{10}$, and Matricaria spp. ${ }^{11}$. Furthermore, essential oils were able to produce synergistic effect when combined with syn- 
thetic antifungal drugs ${ }^{9,12}$.

Syzygium aromaticum (L.) Merr. \& Perry (clove), Piper betle (betel vine), and Ocimum sanctum (holy basil) are common plants in Thailand, and their essential oils are available commercially. The essential oils of these plants have been studied extensively and demonstrated a variety of pharmacological activities. Previous studies showed that clove oil possesses antibacterial, antifungal, and antioxidant activities ${ }^{6,13}$. Betel vine ${ }^{14,15}$ and holy basil essential oils $^{12,16,17}$ have also shown similar activities in various studies. However, none of these reports studied their activities against canine dermatophytes. The present study evaluated antidermatophytic activities of essential oils from $S$. aromaticum, $P$. betle, and $O$. sanctum against clinical isolates and standard strains of canine dermatophytes.

\section{MATERIALS AND METHODS}

\section{Essential oils}

The essential oils of $S$. aromaticum, $P$. betle, and $O$. sanctum were purchased from Thai China Flavours \& Fragrances Industry Co. (Thailand).

\section{Dermatophytes}

Clinical isolates and standard strains of canine dermatophytes were used in this study. The clinical isolates of Trichophyton mentagrophytes, Microsporum canis, and Microsporum gypseum were obtained from the Veterinary Teaching Hospital, Khon Kaen University, Thailand. The standard strains included T. mentagrophytes (DMST 19735), M. canis (DMST 29297), and M. gypseum (DMST 21146) which were obtained from the Department of Medical Sciences, Ministry of Public Health, Thailand. All fungal strains were maintained and subcultured on Sabouraud dextrose agar (SDA, Becton Dickenson) at $28^{\circ} \mathrm{C}$.

\section{Determination of MIC and MFC}

The minimal inhibitory concentration (MIC) of essential oils was determined by broth microdilution assay. Essential oils $(50 \mu \mathrm{l})$ were serially diluted (50-0.024 $\mu \mathrm{l} / \mathrm{ml}$ ) with Sabouraud dextrose broth (SDB, Becton Dickenson) containing DMSO as a solubilizer in a microtitre plate. Ketoconazole (SigmaAldrich) in DMSO, as a control agent, was similarly diluted $(250-0.122 \mu \mathrm{g} / \mathrm{ml})$. An equal volume of the inoculum suspension $\left(10^{6} \mathrm{CFU} / \mathrm{ml}\right)$ of each organism was added to each well. Growth and sterility controls were included for each assay and all tests were performed in triplicate. The microplates were incubated at $28^{\circ} \mathrm{C}$ for 7 days. Endpoint evaluation was performed visually based on comparison of the fungal growth in wells containing essential oil with that of the growth control. The MIC was defined as the lowest concentration at which no visible growth was observed.

To determine the minimal fungicidal concentration (MFC), $20 \mu \mathrm{l}$ of samples from all wells with complete growth inhibition and from the last well showing growth were inoculated onto the surface of Sabouraud dextrose agar Petri dishes. The dishes were incubated at $28^{\circ} \mathrm{C}$ for 3 days or until fungal growth was observed in the control samples. The MFC values were determined as the lowest concentration of essential oils giving no visible growth.

\section{Determination of essential oil components using GC/MS}

The chromatographic analyses were carried out with gas chromatography (Model US35120382, Agilent, China) coupled with a mass spectrometer (Model CN10402086, Agilent, USA). A DB-5ms capillary column $(30 \mathrm{~m} \times 0.25 \mathrm{~mm}$ i.d.) coated with $0.25 \mu \mathrm{m}$ film 5\% phenyl methylpolysiloxane was used for separation. The column temperature started with $70^{\circ} \mathrm{C}$ for $5 \mathrm{~min}$, subsequently increased to $120^{\circ} \mathrm{C}$ at $3{ }^{\circ} \mathrm{C} / \mathrm{min}$ then programmed at $5^{\circ} \mathrm{C} / \mathrm{min}$ to $270^{\circ} \mathrm{C}$ for $3 \mathrm{~min}$. Manual injection $(1 \mu \mathrm{l})$ in a purged split mode (1:100) was conducted and high-purity helium was used as carrier gas at $1 \mathrm{ml} / \mathrm{min}$ flow rate. The scan range was $35-550 \mathrm{~m} / \mathrm{z}$ and the scan rate was 1000 atomic mass unit per second (amu/s). Injected volume was $1 \mu \mathrm{l}$ of $1 \%$ solution (diluted in hexane). The identification of the components was based on comparison of their mass spectra with those of a computer library (Wiley 7n MS Search library).

\section{RESULTS}

\section{MIC and MFC}

The MIC and MFC values are shown in Table 1. The three essential oils are effective against all dermatophyte strains at very low concentrations. The MICs ranged from $0.2-1.6 \mu \mathrm{l} / \mathrm{ml}$, and the MFCs from $0.4-1.6 \mu \mathrm{l} / \mathrm{ml}$. The MIC and MFC ranges of ketoconazole are $0.12-050$ and $0.25-0.50 \mu \mathrm{g} / \mathrm{ml}$, respectively. Among the three essential oils, antifungal activity of $S$. aromaticum is the highest, and $O$. sanctum is the lowest. In the view of dermatophytes, the sensitivities of clinical isolates and standard strains are not different. However, $M$. gypseum needed twice the drug concentration 
Table 1 Antifungal activity (MIC and MFC) of the essential oils of S. aromaticum, P. betle, and O. sanctum against dermatophyte strains.

\begin{tabular}{|c|c|c|c|c|c|c|c|c|}
\hline \multirow[t]{2}{*}{ Dermatophytes } & \multicolumn{2}{|c|}{ S. aromaticum } & \multicolumn{2}{|c|}{ P. betle } & \multicolumn{2}{|c|}{ O. sanctum } & \multicolumn{2}{|c|}{ Ketoconazole } \\
\hline & $\mathrm{MIC}^{\mathrm{a}}$ & $\mathrm{MFC}^{\mathrm{a}}$ & $\mathrm{MIC}^{\mathrm{a}}$ & $\mathrm{MFC}^{\mathrm{a}}$ & $\mathrm{MIC}^{\mathrm{a}}$ & $\mathrm{MFC}^{\mathrm{a}}$ & $\mathrm{MIC}^{\mathrm{b}}$ & $\mathrm{MFC}^{\mathrm{b}}$ \\
\hline \multicolumn{9}{|l|}{ Clinical isolates $^{\dagger}$} \\
\hline T. mentagrophytes $(n=5)$ & 0.2 & 0.4 & $0.2-0.4$ & 0.4 & 0.8 & 0.8 & 0.12 & 0.25 \\
\hline M. canis $(n=10)$ & $0.2-0.4$ & 0.4 & $0.2-0.4$ & 0.4 & $0.4-0.8$ & 0.8 & 0.12 & 0.25 \\
\hline M. gypseum $(n=5)$ & 0.4 & 0.4 & $0.4-0.8$ & 0.8 & 1.6 & 1.6 & 0.50 & 0.50 \\
\hline \multicolumn{9}{|l|}{ Standard strains } \\
\hline T. mentagrophytes DMST 19735 & 0.2 & 0.4 & $0.2-0.4$ & 0.4 & 0.8 & 0.8 & 0.12 & 0.25 \\
\hline M. canis DMST 29297 & 0.2 & 0.4 & 0.2 & 0.4 & 0.4 & 0.8 & 0.12 & 0.25 \\
\hline M. gypseum DMST 21146 & 0.4 & 0.4 & 0.8 & 0.8 & 1.6 & 1.6 & 0.50 & 0.50 \\
\hline
\end{tabular}

${ }^{a}$ MIC and MFC in $\mu \mathrm{l} / \mathrm{ml}(\mathrm{v} / \mathrm{v})$.

${ }^{\mathrm{b}}$ MIC and MFC in $\mu \mathrm{g} / \mathrm{ml}(\mathrm{w} / \mathrm{v})$.

$\dagger n=$ number of isolates.

Table 2 GC/MS analysis of essential oils of $S$. aromaticum, $P$. betle, and $O$. sanctum.

\begin{tabular}{|c|c|c|c|}
\hline Components & $\begin{array}{l}\text { Molecular } \\
\text { formula }\end{array}$ & $\begin{array}{c}\text { Retention } \\
\text { time (min) }\end{array}$ & $\begin{array}{l}\% \text { of } \\
\text { total }\end{array}$ \\
\hline \multicolumn{4}{|l|}{ S. aromaticum } \\
\hline eugenol & $\mathrm{C}_{10} \mathrm{H}_{12} \mathrm{O}_{2}$ & 23.37 & 98.9 \\
\hline trans-caryophyllene & $\mathrm{C}_{15} \mathrm{H}_{24}$ & 26.35 & 1.1 \\
\hline \multicolumn{4}{|l|}{ P. betle } \\
\hline$p$-chavicol & $\mathrm{C}_{11} \mathrm{H}_{12} \mathrm{O}_{2}$ & 22.71 & 4.9 \\
\hline eugenol & $\mathrm{C}_{10} \mathrm{H}_{12} \mathrm{O}_{2}$ & 24.12 & 38.7 \\
\hline trans-caryophyllene & $\mathrm{C}_{15} \mathrm{H}_{24}$ & 26.35 & 4.0 \\
\hline$\alpha$-amorphene & $\mathrm{C}_{15} \mathrm{H}_{24}$ & 28.52 & 4.4 \\
\hline cubebene & $\mathrm{C}_{15} \mathrm{H}_{24}$ & 28.71 & 3.1 \\
\hline$\delta$-cadinene & & & \\
\hline or $\delta$-amorphene & $\mathrm{C}_{15} \mathrm{H}_{24}$ & 30.00 & 2.5 \\
\hline eugenol acetate & $\mathrm{C}_{12} \mathrm{H}_{14} \mathrm{O}_{3}$ & 30.12 & 23.4 \\
\hline 4-allyl-1,2- & & & \\
\hline diacetoxybenzene & $\mathrm{C}_{13} \mathrm{H}_{14} \mathrm{O}_{4}$ & 33.36 & 19.1 \\
\hline \multicolumn{4}{|l|}{ O. sanctum } \\
\hline eugenol & $\mathrm{C}_{10} \mathrm{H}_{12} \mathrm{O}_{2}$ & 23.23 & 8.7 \\
\hline$\beta$-elemene & $\mathrm{C}_{15} \mathrm{H}_{24}$ & 25.09 & 4.5 \\
\hline methyl eugenol & $\mathrm{C}_{11} \mathrm{H}_{14} \mathrm{O}_{2}$ & 25.73 & 52.4 \\
\hline trans-caryophyllene & $\mathrm{C}_{15} \mathrm{H}_{24}$ & 26.37 & 29.3 \\
\hline$\alpha$-humulene & $\mathrm{C}_{15} \mathrm{H}_{24}$ & 27.77 & 1.7 \\
\hline$\beta$-cubebene & $\mathrm{C}_{15} \mathrm{H}_{24}$ & 28.71 & 1.8 \\
\hline$\beta$-elemene & $\mathrm{C}_{15} \mathrm{H}_{24}$ & 29.61 & 1.6 \\
\hline
\end{tabular}

compared to the others.

\section{GC/MS analysis}

Components of the three essential oils analysed by GC/MS are shown in Table 2. The compositions differed widely among the three oils. Two compounds were found in $S$. aromaticum essential oil of which eugenol (99\%) was the principal component followed by trans-caryophyllene (1\%). The major components of $P$. betle essential oil was eugenol (39\%), eugenol acetate (23\%), and 4-allyl-1,2-diacetoxybenzene (19\%). The major components of O. sanctum essential oil were methyl eugenol (52\%), trans-caryophyllene (29\%), eugenol (9\%), and $\beta$ elemene (5\%).

\section{DISCUSSION}

To be used as topical antifungal agent in veterinary medicine, essential oils possess several advantages in addition to their antimicrobial activities. Firstly, most of them demonstrate antioxidant activity that could help alleviate inflammation ${ }^{18}$. Secondly, essential oils are derived from plants and contain mixture of active components which may result in additive or synergistic effects or having action at multiple targets ${ }^{19}$. Thirdly, mechanisms of antifungal resistance are usually related to receptor-mediated action of antifungal drugs, therefore, essential oils that act hypothetically by their hydrophobicity and interfere with cell membrane structure may overcome the fungal resistance mechanism ${ }^{6,20}$. Lastly, essential oils have less toxicity when used on skin, with the most common adverse effect being irritation $^{6}$.

The results of this study initially revealed the nature of the two groups of tested dermatophyte samples. Standard strains and clinical isolates had the same susceptibility profiles for all species of dermatophytes as evidenced by similar MIC and MFC values of all essential oils and ketoconazole shown in Table 1 . These dermatophytes were also considered to be non-resistant population as their responses to ketoconazole (MIC range 0.125- 
$0.5 \mu \mathrm{g} / \mathrm{ml}$ ) were in the lower scale compared to the MIC range $(0.125-16 \mu \mathrm{g} / \mathrm{ml})$ reported by the others $^{10,21,22}$.

In view of fungal sensitivity, the MIC and MFC obtained in this study could be presented as $M$. gypseum $>M$. canis $=T$. mentagrophytes for all tested essential oils and ketoconazole. These findings are in agreement with other reports demonstrating more resistant characteristics of $M$. gypseum than the other two ${ }^{10,23}$.

In view of the potency of essential oils, all these three essential oils possessed strong antifungal activities with small differences. The comparative effects were demonstrated by their MIC and MFC and could be presented as $S$. aromaticum $>P$. betle $>$ O. sanctum for all dermatophytes tested. The differences in activities of these essential oils were also demonstrated by several reports. Our previous report showed equal activities of $S$. aromaticum and P. betle essential oils on Malassezia pachydermatis ${ }^{24}$. A study that compared activity of essential oils on Enterococcus faecalis showed higher activity of S. aromaticum than $O$. sanctum ${ }^{25}$.

The results of this study can also be compared to other essential oils that were studied on dermatophytes. A recent study demonstrated antifungal activities of twenty commercial essential oils and three of them were identified as highly active ${ }^{26}$. These essential oils are of Thymus serpyllum (MIC range $0.25-2.5 \mu \mathrm{l} / \mathrm{ml}$ ), Origanum vulgare (MIC range $0.25-5.0 \mu \mathrm{l} / \mathrm{ml}$ ), and Litsea cubeba (MIC range $0.25-1.5 \mu \mathrm{l} / \mathrm{ml}$ ). In comparison, our three tested essential oils could be also identified as highly active as they had a similar MIC range.

In relation to our findings, antifungal activities of these essential oils were strengthened in both efficacy and spectrum by other studies. S. aromaticum essential oil was able to inhibit growth of Candida $^{23,27}$ Aspergillus $^{23,28}$, Fusarium ${ }^{28}$, Epidermophyton ${ }^{23,27}$, Trichophyton ${ }^{23,27,28}$, and Microsporum $^{23,27,28}$ species. P. betle essential oil was also able to inhibit growth of Candida ${ }^{29}$, Malassezia ${ }^{24}$, Aspergillus ${ }^{14}$, Penicillium ${ }^{14}$, Fusarium ${ }^{14}$, and Cladosporium ${ }^{14}$ species. O. sanctum essential oil too was able to inhibit growth of Candida ${ }^{12,30}$, Aspergillus $^{16,31}$, Penicillium $^{16,31}$, Fusarium $^{16}$, and Cladosporium ${ }^{16}$ species. Even though these reports used different methods and fungal organisms, they support that antifungal activities of these essential oils are highly active and broad-spectrum.

Once these essential oils have been categorized as highly active, further investigations for clinical use are needed. The possibility is supported by several recent reports showing effectiveness of other essential oils for treating animal dermatophytosis in vivo. In one study, $25 \%$ tea tree oil was able to treat 30 thoroughbred horses infected with Trichophyton equinum $^{32}$. In other studies, $2 \%$ essential oil of T. serpyllum and $5 \%$ essential oil of $O$. vulgare were able to cure cats infected with $M$. canis $^{33}$, and sheep infected with T. mentagrophytes ${ }^{34}$. A mixture of essential oils was also reported to effectively treat dogs with Malassezia dermatitis within 1 month $^{35}$. Based on these reports, our tested essential oils may be able to produce a favourable result in vivo if tested. The intended clinical application of our laboratory is to develop semi-solid preparations for topical use, and we are formulating two types of preparation: cream and ointment, for future studies.

Compositions of essential oils in plants are generally varied depending on many factors such as time of harvest, part of the plant, environment, or species variations. In addition, extraction method may change the composition of the resultant essential oil extract. These composition variations also affect their biological activities and may partly explain differences among publications. In this study, we analysed all essential oils using GC/MS analysis, and the major constituents of the essential oils are shown in Table 2. S. aromaticum essential oil contained mostly eugenol (99\%) which is believed to be the active substance and is well known for its antimicrobial activity ${ }^{13}$. P. betle essential oil contained two major constituents, eugenol and eugenol acetate (total of $62 \%$ ). As the antifungal activity of $P$. betle essential oil was similar to that of $S$. aromaticum, we may assume that both substances are active on dermatophytes. However, eugenol acetate was shown to have lower antimicrobial activity than eugenol ${ }^{36}$. O. sanctum essential oil contains methyl eugenol as the major constituent (52\%), followed by trans-caryophyllene (29\%), and eugenol is only a minor constituent (9\%). Methyl eugenol has been shown to have similar antimicrobial activity to eugenol ${ }^{31}$, while trans-caryophyllene has shown no antimicrobial activity ${ }^{37}$. Thus methyl eugenol and eugenol (total of 61\%) appear to be the major active substances. The difference in eugenol and eugenol derivatives may explain why $S$. aromaticum essential oil had more activity and $O$. sanctum had less activity. The mechanisms of eugenol antifungal activity have been previously proposed as disruption of cell membrane fluidity and permeability which then inhibits fungal growth and eventually causes cell death ${ }^{19,38}$.

In conclusion, the essential oils of $S$. aro- 
maticum, $P$. betle, and $O$. sanctum which are local and abundant in Thailand were demonstrated to be highly active antifungal agents against canine dermatophytes in vitro. The level of activity was comparable to those previously shown to be effective in treating dermatophytes in several species. The major active substances in these oils were eugenol and its derivatives. Further experiments in infected animals will prove their potential as alternative antifungal agents.

Acknowledgements: This study was supported by the Faculty of Veterinary Medicine, Khon Kaen University.

\section{REFERENCES}

1. Mattei AS, Beber MA, Madrid IM (2014) Dermatophytosis in small animals. SOJ Microbiol Infect Dis 2(3), 1-6.

2. Mani I, Maguire JH (2009) Small animal zoonoses and immunocompromised pet owners. Top Companion Anim Med 24, 164-74.

3. Moriello KA (2004) Treatment of dermatophytosis in dogs and cats: review of published studies. Vet Dermatol 15, 99-107.

4. Taboada J, Grooters AM (2008) Systemic antifungal therapy. In: Maddison JE, Page SW, Church DB (eds) Small Animal Clinical Pharmacology, Saunders Elsevier, Philadelphia, pp 186-97.

5. White TC, Marr KA, Bowden RA (1998) Clinical, cellular, and molecular factors that contribute to antifungal drug resistance. Clin Microbiol Rev 11, 382-402.

6. Raut JS, Karuppayil SM (2014) A status review on the medicinal properties of essential oils. Ind Crop Prod 62, 250-64.

7. Mahboudi M, Kazempour N (2015) The antifungal activity of Artemisia sieberi essential oil from different localities of Iran against dermatophyte fungi. $J \mathrm{Mycol}$ Méd 25, e65-71.

8. Mastura M, Nor Azah MA, Khozirah S, Mawardi R, Manaf AA (1999) Anticandidal and antidermatophytic activity of Cinnamomum species essential oils. Cytobios 98, 17-23.

9. Pyun MS, Shin S (2006) Antifungal effects of the volatile oils from Allium plants against Trichophyton species and synergism of the oils with ketonazole. Phytomedicine 13, 394-400.

10. Mahmoudvand H, Sepahvand A, Jahanbakhsh S, Ezatpour B, Ayatollahi Mousavi SA (2014) Evaluation of antifungal activities of the essential oil and various extracts of Nigella sativa and its main component, thymoquinone against pathogenic dermatophyte strains. J Mycol Méd 24, e155-61.

11. Jamalian A, Shams-Ghahfarokhi M, Jaimand K, Pashootan N, Amani A, Razzaghi-Abyaneh M (2012) Chemical composition and antifungal activity of $M a$ - tricaria recutita flower essential oil against medically important dermatophytes and soil-borne pathogens. J Mycol Méd 22, 308-15.

12. Amber K, Aijaz A, Immaculata X, Luqman KA, Nikhat M (2010) Anticandidal effect of Ocimum sanctum essential oil and its synergy with fluconazole and ketoconazole. Phytomedicine 17, 921-5.

13. Chaieb $\mathrm{K}$, Hajlaoui $\mathrm{H}$, Zmantar T, Kahla-Nakbi AB, Rouabhia M, Mahdouani K, Bakhrouf A (2007) The chemical composition and biological activity of clove essential oil, Eugenia caryophyllata (Syzigium aromaticum L. Myrtaceae): a short review. Phytother Res 21, 501-6.

14. Prakash B, Shukla R, Singh P, Kumar A, Mishra PK, Dubey NK (2010) Efficacy of chemically characterized Piper betle L. essential oil against fungal and aflatoxin contamination of some edible commodities and its antioxidant activity. Int J Food Microbiol 142, 114-9.

15. Garg SC, Jain R (1992) Biological activity of the essential oil of Piper betle L. J Essent Oil Res 4, 601-6.

16. Kumar A, Shukla R, Singh P, Dubey NK (2010) Chemical composition, antifungal and antiaflatoxigenic activities of Ocimum sanctum L. essential oil and its safety assessment as plant based antimicrobial. Food Chem Toxicol 48, 539-43.

17. Mahajan N, Rawal S, Verma M, Poddar M, Alok S (2013) A phytopharmacological overview on Ocimum species with special emphasis on Ocimum sanctum. Biomed Prev Nutr 3, 185-92.

18. Amorati R, Foti MC, Valgimigli L (2013) Antioxidant activity of essential oils. J Agr Food Chem 61, 10835-47.

19. Bassolé IH, Juliani HR (2012) Essential oils in combination and their antimicrobial properties. Molecules 17, 3989-4006.

20. Solórzano-Santos F, Miranda-Novales MG (2012) Essential oils from aromatic herbs as antimicrobial agents. Curr Opin Biotechnol 23, 136-41.

21. Araújo CR, Miranda KC, Fernandes OFL, Soares AJ, Silva MRR (2009) In vitro susceptibility testing of dermatophytes isolated in Goiania, Brazil, against five antifungal agents by broth microdilution method. Rev Inst Med Trop S Paulo 51, 9-12.

22. Aala F, Yusuf UK, Rezaie S, Davari B, Aala F (2011) In vitro antifungal effects of aqueous garlic extract alone and in combination with azoles against dermatophytic fungi. Int Res $J$ Biochem Bioinformat 1, 226-31.

23. Pinto E, Vale-Silva L, Cavaleiro C, Salgueiro L (2009) Antifungal activity of the clove essential oil from Syzygium aromaticum on Candida, Aspergillus and dermatophyte species. J Med Microbiol 58, 1454-62.

24. Asawapattanakul T, Khunkitti W, Leesing R, Aiemsaard J (2013) The efficacy of essential oils against Malassezia pachydermatis isolated from canine otitis externa. Isan J Pharmaceut Sci 9(1), 40-51, [in Thai]. 
25. Gupta A, Duhan J, Tewari S, Sangwan P, Yadav A, Singh G, Juneja R, Saini H (2013) Comparative evaluation of antimicrobial efficacy of Syzygium aromaticum, Ocimum sanctum and Cinnamomum zeylanicum plant extracts against Enterococcus faecalis: a preliminary study. Int Endod $J$ 46, 775-83.

26. Nardoni S, Giovanelli S, Pistelli L, Mugnaini L, Profili G, Pisseri F, Mancianti F (2015) In vitro activity of twenty commercially available, plant-derived essential oils against selected dermatophyte species. Nat Prod Comm 10, 1473-8.

27. Chee HY, Lee MH (2007) Antifungal activity of clove essential oil and its volatile vapour against dermatophytic fungi. Mycobiology 35, 241-3.

28. Rana IS, Rana AS, Rajak RC (2011) Evaluation of antifungal activity in essential oil of the Syzygium aromaticum (L.) by extraction, purification and analysis of its main component eugenol. Braz J Microbiol 42, 1269-77.

29. Makkar N, Prasanna SB, Singla H (2017) Comparative evaluation of antifungal activity of Piper betle leaf oil, Origamum vulgare essential oil and fluconazole suspension on Candida albicans - an in vitro study. J Indian Assoc Publ Health Dent 15, 89-93.

30. Taweechaisupapong S, Aieamsaard J, Chitropas P, Khunkitti W (2012) Inhibitory effect of lemongrass oil and its major constituents on Candida biofilm and germ tube formation. S Afr J Bot 81, 95-102.

31. Joshi RK (2013) Chemical composition, in vitro antimicrobial and antioxidant activities of the essential oil of Ocimum gratissimum, $O$. sanctum and their major constituents. Indian J Pharmaceut Sci 75, 457-62.

32. Pisseri F, Bertoli A, Nardoni S, Pinto L, Pistelli L, Guidi G, Mancianti F (2009) Antifungal activity of tea tree oil from Melaleuca alternifolia against Trichophyton equinum: an in vivo assay. Phytomedicine 16, 1056-8.

33. Mugnaini L, Nardoni S, Pinto L, Pistelli L, Leonardi M, Pisseri F, Mancianti F (2012) In vitro and in vivo antifungal activity of some essential oils against feline isolates of Microsporum canis. J Mycol Méd 22, 179-84.

34. Mugnaini L, Nardoni S, Pistelli L, Leonardi M, Giuliotti L, Benvenuti MN, Pisseri F, Mancianti F (2013) A herbal antifungal formulation of Thymus serpillum, Origamum vulgare and Rosmarinus officinalis for treating ovine dermatophytosis due to Trichophyton mentagrophytes. Mycoses 56, 333-7.

35. Nardoni S, Mugnaini L, Pistelli L, Leonardi M, Sanna V, Perrucci S, Pisseri F, Mancianti F (2014) Clinical and mycological evaluation of an herbal antifungal formulation in canine Malassezia dermatitis. $J$ Mycol Méd 24, 234-40.

36. Vanin AB, Orlando T, Piazza SP, Puton BMS, Cansian RL, Oliveira D, Paroul N (2014) Antimicrobial and antioxidant activities of clove essential oil and eugenyl acetate produced by enzymatic esterification. Appl Biochem Biotechnol 174, 1286-98.
37. Bougatsos C, Ngassapa O, Runyoro DKB, Chinou IB (2004) Chemical composition and in vitro antimicrobial activity of the essential oils of two Helichrysum species from Tanzania. Z Naturforsch C 59, 368-72.

38. Kamatou GP, Vermaak I, Viljoen AM (2012) Eugenol-from the remote Maluku islands to the international market place: a review of a remarkable and versatile molecule. Molecules 17, 6953-81. 